\title{
Impact of Nuclear Tests on Deforestation in North Korea using Google Earth-Based Spatial Images
}

\author{
Junghoon $\mathrm{Ki}^{1,2,3^{*}}$, Minki Sung ${ }^{4}$, and Choongik Choi ${ }^{5}$ \\ ${ }^{1}$ Department of Public Administration, School of Social Science, Myongji University, Seoul 03674, Korea \\ ${ }^{2}$ Big Data Analytics Center, Myongji University, Seoul 03674, Korea \\ ${ }^{3}$ GeODesign Institute, Myongji University, Seoul 03674, Korea \\ ${ }^{4}$ Graduate School of Record, Archives \& Information Science, Myongji University, Seoul 03674, Korea \\ ${ }^{5}$ Department of Public Administration, School of Social Science, Kangwon National University, Gangwon 24341, Korea
}

\section{ABSTRACT}

The North Korean government conducted its first nuclear test in 2006 and more recently the sixth nuclear test on September 3, 2017. In order to identify how North Korea's nuclear tests have affected the environment, a scientific approach is required. Although North Korea's nuclear tests and their environmental destruction are not a severe threat to the environment of the Korean Peninsula at this time, identifying environmental damage and taking countermeasures in advance are essential to minimize their potential threats to the environments. The purpose of this study is to study the environmental impact of North Korea's nuclear tests using Google Earth image analysis.

As a method of the study, we compare Google Earth images taken before and after each nuclear test was conducted in North Korea. To overcome limitations of the suggested comparison method, we cross-checked our results with those of previous scientific research. After the 1st-3rd nuclear tests, green spaces were found to be considerably reduced. In particular, when comparing the Google Earth images before and after the second nuclear test, some ground subsidences were observed. Such subsidences can cause tunnels on the mountainsides and cracks in rocks around the mountains, leading to the release of radioactive materials and contaminating groundwater. Besides, after the 4th-6th nuclear tests, decay and deforestation were observed not in the nuclear test sites, but in their surrounding areas. Especially after the 5th and 6th nuclear tests, the topography and the forests of the surrounding areas were severely damaged. In relation to North Korea's nuclear tests and their impact on the natural environment, we need to prepare various policy measures to reduce North Korea's environmental pollution and natural environment destruction. Those policy measures include the establishment of various cooperative governance between the Korean government, the private sector, the academia, NGOs, and international organizations.

Keywords: deforestation, environmental destruction, Google Earth image, nuclear testing

\section{Introduction}

North Korea conducted its first nuclear test in 2006, and most recently the sixth nuclear test on September 3, 2017. As it has continued to conduct nuclear tests, their explosive power has also increased (Jang, 2017). As the maximum pow- er of the nuclear test site in Punggye-ri, Hamgyeongbuk-do surpassed the maximum estimated power of the sixth nuclear test, $160 \mathrm{kt}$, and reached $200 \mathrm{kt}$, there is a growing concern about the possibility that the mountains near the site of which ground has already been weakened due to the repeated nuclear tests can collapse if nuclear tests are

\footnotetext{
This study was conducted under the basic research project (No.: NRF-2014R1A1A2056499) supported by the National Research Foundation of Korea with the budget supported by the government (Ministry of Education) in 2014. This work was supported by 2019 Research Fund of Myongji University.

Received: October 21, 2019, Revised: November 11, 2019, Accepted: November 24, 2019

First author: Junghoon Ki, johnki@mju.ac.kr, (D) https://orcid.org/0000-0001-7554-9573

*Corresponding author: Junghoon Ki, johnki@mju.ac.kr, (10) https://orcid.org/0000-0001-7554-9573
} 
additionally carried out. In addition, North Korea dug shafts horizontally, not vertically, within the nuclear test site in Punggye-ri, due to problems of cost, which not only raises the possibility of collapse, but also transfers the explosive energy of nuclear tests to its surrounding soil, increasing the possibility of natural earthquakes (Kim, 2017). These natural earthquakes may also lead to fallen caves such as those that occurred after the sixth nuclear test, and when the ground falls and collapses like those fallen caves, the radioactive substances buried can leak out of the ground (Kim, 2017). As the sun emits radiation, all kinds of living things including humans are exposed and adapted to a small amount of radioactive substances inside and outside their body, but the excessive exposure to radioactive substances beyond their permissible level results in a considerable amount of damage (Hong, 1993).

Underground nuclear tests are known to melt rocks within shafts and transform them into hyaline rocks, and they, in turn, block radioactive byproducts, but radioactive substances can flow into nearby veins of water and contaminate groundwater (Ham, 2017). The most serious problem is that it has been little known whether North Korea has properly followed a series of processes for nuclear development, or whether it has conducted nuclear tests with proper safety measures in place. Based on the fragmented information heard from North Korean defectors, people de- scribe North Korea's nuclear disposal very negatively.

North Korea's nuclear tests have raised concerns in the international community, and have significantly affected both its society and security, which has highlighted the importance of collecting national information such as promptly detecting and reliably analyzing additional nuclear tests in North Korea and large-scale explosive phenomena observed in neighboring countries (Je, 2008). In order to identify the impact of nuclear tests in North Korea on surrounding environments, it is required to analyze them based on the results of scientific experiments. Even if North Korea's nuclear tests and their consequent environmental destruction may not pose deadly threats to the environment of the Korean Peninsula right now, it is important to identify their impact and establish measures in advance in order to minimize their potential threats and damage (Jang, 2017).

According to 38 North, a website of Johns Hopkins University in the United States devoted to analysis about North Korea, the sixth nuclear test carried out on September 3, 2017 resulted in numerous landslides throughout the Punggye-ri nuclear test site (Jeon, 2017). The website compared images of the site taken by a commercial satellite on September 1 and 4, and analyzed damage that the sixth nuclear test brought to its surrounding areas (Fig. 1). Traces of numerous landslides were observed near the top of the mountain located near the shaft in the north of the Punggye-ri

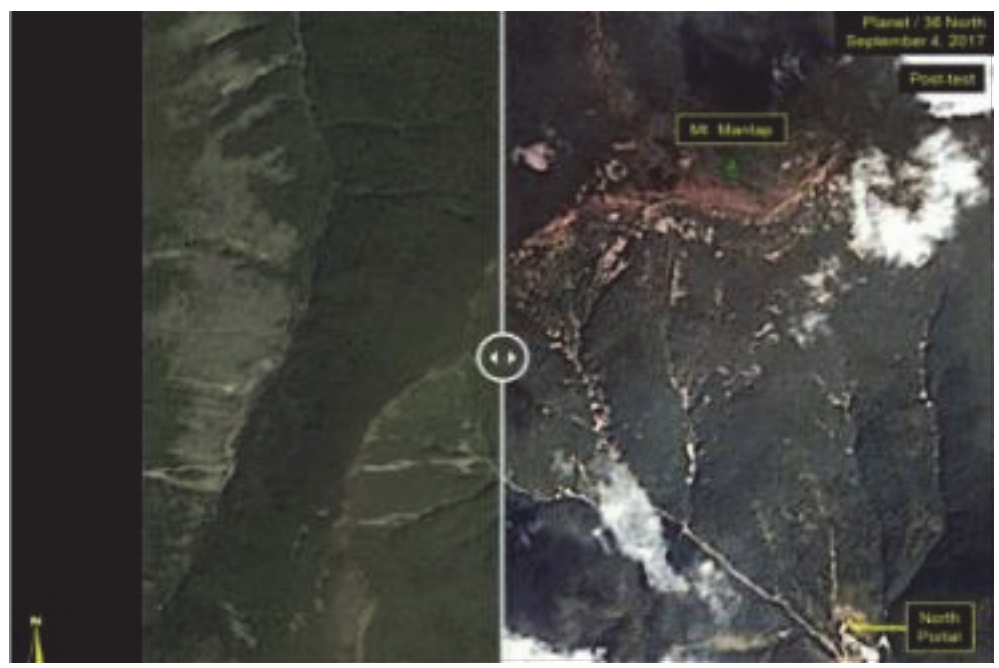

Fig. 1. Photographs around the Punggye-ri nuclear test. Reprinted from "38 North "Northern Punggye-ri mountain range, landslide occurred due to nuclear test'- North Korea's sixth nuclear test has caused extensive regional damage...There's no sign of a breach-" by K.W. Jeon, 2017, September 6, NewDaily. 
nuclear test site after the sixth nuclear test. Traces of landslides, destroyed forests and exposed ground surfaces that were caused by vibration from the nuclear test were observed in broad areas around Mt. Mantap (elevation: 2,205 m) near the nuclear test site. These results indicate that North Korea's nuclear tests pose a serious impact on the destruction of forests near the site, which requires a scientific and systematic approach.

One of the scientific and systematic approaches that can be adopted is the utilization of spatial images taken by satellites. Those images have been utilized in various fields including global environmental management and climate change and more recently in areas closely related to daily life. In particular, various imagery information collected from satellites is utilized in activities related to environment, sea, geology, forestry, agriculture and meteorology, such as producing maps, but also in almost every area where humans are involved. Since these kinds of imagery information collected from satellites differ depending on their characteristics such as spatial resolution, spectral resolution, temporal resolution, etc., areas of utilization are very broad (Cho, 2015). In particular, Google Earth utilized in this study is a satellite-based spatial information service provided by Google, a multinational company, and provides $2.5 \mathrm{~m}$-resolution SPOT images as basic data $(\mathrm{Ki}$, 2016; Kim, et al., 2012). Google Earth seems to be the most useful data source that can replace a limited amount of environmental and geographic information on North Korea (Kim, et al., 2012).

There are still some difficulties in handling environmental pollution such as radioactivity in detail through spatial images of Google Earth, but it is encouraging to see that Google Earth continues to evolve as advanced technology has been adopted. For instance, the level of fine dust that comes from China to Korea can be observed in real time through Google Earth Nullschool (earth.nullschool) that provides the concentration and path of fine dust or carbon monoxide that are collected and visualized by GEOS-5, an Earth observing system operated by the National Aeronautics and Space Administration (NASA) of the United States. In addition, the SERVIR-HKH (Hindu Kush Himalaya) Initiative of the International Centre for Integrated Mountain Development (ICIMOD) is currently developing numerous application programs for Google Earth Engine (GEE). GEE is a cloud computing platform that remotely senses and analyzes spatial and temporal data, and it can be used to conduct large- and small-scale scientific analysis, visualize geospatial data, and thus to save, compose and access satellite images and geospatial data. This platform provides not only tools and cloud computing services for large-scale data analysis, but also JavaScript and Phython application program interfaces (APIs). This kind of advanced technology in areas such as spatial images is expected to be utilized in analyzing very restricted and closed regions like North Korea. The purpose of this study is to examine the impact of nuclear tests on the environment of North Korea by analyzing Google Earth images, particularly focusing on the destruction of forests that can be clearly identified on Google Earth images.

\section{Research Methods}

\section{Earlier studies}

As GIS-based spatial information services provided through the Internet are increasingly common today, various and precise spatial information that was not accessible in the past are available free of charge today. One of the most popular services is Google Earth, a spatial information service provided by Google, a multinational company, based on satellite spatial images. Google Earth has been utilized in various areas, and, in particular, it has been actively utilized to acquire geographic information on disaster and devastated areas of which changes over time are hardly accessible, and to identify the routes of spread by country.

Scientists around the world utilize Google Earth for various purposes for humanity such as predicting different types of natural disasters to secure the safety of airplanes, researching global warming, and tracing avian flue variations and the routes of spread. Moreover, it is also used to figure out the decisive evidence of global warming, and to forecast the melting of permanent snow caused by global warming. The National Snow and Ice Data Center (NSIDC) of Colorado University in the United States has continued to analyze satellite images to research glaciers in the polar 
areas, and also successfully proved the seriousness of global warming by animating the images of glaciers in the Arctic in a time-ordered sequence utilizing Google Earth. The NSIDC reported that over $50 \%$ of sea ice in the Arctic was melted within only two months.

Dr. Daniel Janies, a zoologist at the Ohio State University, tried to trace the routes of spread and variation process of H5N1 avian influenza that can infect humans by country utilizing Google Earth, and found that the share of abnormal routes such as bird smuggling, and other routes without transmission between birds or migratory birds is increasing.

Above all, the area that can show a significant amount of achievements by applying Google Earth to scientific research is predicting and monitoring natural disasters. The research team of Dr. Peter Webley in the Institute of Volcanology at University of Alaska developed the Precise Point Positioning (PPP) program for volcanic ash utilizing Google Earth, which highlights the utility of Google Earth. The Real Time Mission Monitor (RTMM) is a tool that integrates meteorological images updated in real time every minute through Google Earth with the flight paths of research aircraft, playing a key role in helping aircraft approach hurricanes avoiding unexpected risk factors such as lightning or gusts.

As such, Google Earth is mainly used to preemptively prevent disasters and to secure the safety of humans, but when natural disasters occur, it can be utilized to establish plans for rescue. It is because situations in disaster areas can be monitored in real time through Google Earth. It also allows to develop maps of emotions that integrate geographic information with sensory information, supporting reasonable urban development. Christian Nold, a designer in the United Kingdom, built data on emotional reactions of people towards certain urban areas, integrated them with Google Earth and created the world's first two-way map that showed geographic information and human emotions simultaneously. As the map of emotions shows how people react to certain social places such as parks and squares, and to which point of intersection of roads people tend to show more emotional reactions, it can be utilized in establishing basic guidelines for urban development or plans for reasonable urban development.

In this study, Google Earth, an Internet-based geographic information service, was utilized as an alternative in order to overcome the limits of conventional geographic information. Google Earth provides satellite images of over $2.5 \mathrm{~m}$ spatial resolution as basic data. For large cities or certain facilities, it provides $1 \mathrm{~m}$ high-resolution satellite images. As Fig. 1 shows, most of the high-resolution satellite images of North Korea provided by Google Earth were taken before 2000, covering nearly every region of North Korea. The high-resolution satellite images provided by Google Earth show the date and year when the images were taken (Fig. 2).

In addition, there has been almost no study in Korea that researched the impact of nuclear tests on the environment of forests that will be examined through Google Earth in this study, and only few studies examined the destruction of forests.

People in North Korea have cut down trees in mountains for firewood, which turned them into bare mountains, and reduced the area of forests in North Korea by $30 \%$ over the past two decades (Song, 2012). The 'excessive conversion of forests into terraced fields' has devastated forests in North Korea. The unplanned 'development of terraced

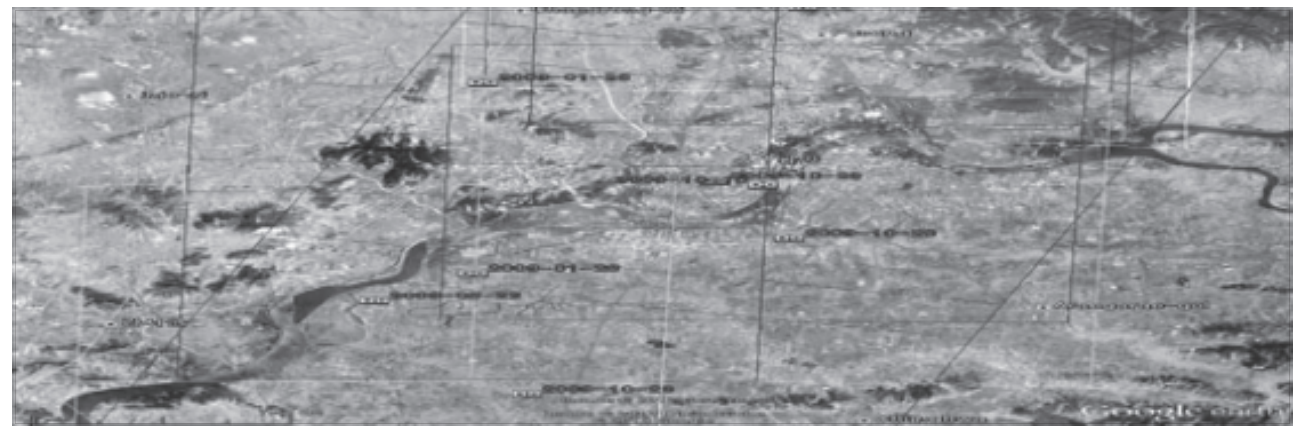

Fig. 2. Date of high resolution satellite image captured in Pyongyang. 
fields' and the 'new land development project' have been pointed out as one of the causes of the worst-ever flood damage in the mid-1990s in North Korea (Jung and Byun, 2011). In particular, regions like Hwanghaenam-do and Hwanghaebuk-do have relatively more low hills and slopes than other regions have experienced serious forest destruction due to the development of terraced fields and the new land development project that were conducted in order to secure agricultural lands. In addition, forest destruction and environmental pollution were found to broadly spread across North Korea centering on industrial cities (Ki, 2016).

For this reason, it will be important to identify and establish measures against the effects of nuclear tests and consequent environmental destruction on the Korean Peninsula, even if they does not pose immediate deadly threats, in order to minimize damage from potential threats (Jang, 2017). Most of the studies conducted in Korea, however, focus on political and economic environments associated with North Korea's nuclear tests. Some studies were conducted in other countries on environmental destruction caused by nuclear tests, but they also researched their impact on the atmosphere, air, sea, soil, plants and humans only (Pravalie, 2014). There has been no study that focused on forest destruction by nuclear tests. For this reason, this study that examines the impact of North Korea's nuclear tests on environment, especially forest destruction, utilizing Google Earth is expected to give various implications.

\section{Methods}

With the aim of examining the environmental impact of North Korea's nuclear test based on Google Earth spatial images, this study selected as a research subject the nuclear test site at Punggye-ri, Gilju-gun, Hamgyeongbuk-do, North Korea. North Korea conducted its first nuclear test in 2006, and most recently the sixth nuclear test in September, 2017 (Fig. 3, Table 1).

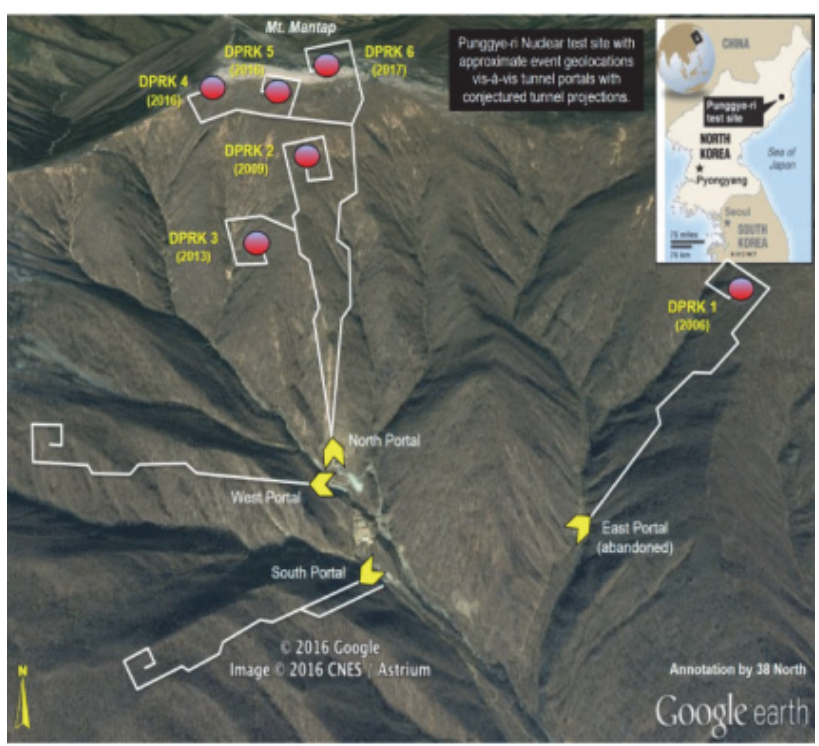

D. Image Google Earth annotation by 38 North

Fig. 3. Punggye-ri nuclear tests' site map. Reprinted from "The Punggye-ri Nuclear Test Site: A Test Tunnel Tutorial" by F.V. Pabian, 2018, May 23, 38 NORTH.

https://www.38north.org/2018/05/punggyetunnel052318/

Table 1. Comparison of past and present images through Google Earth according to nuclear test date

\begin{tabular}{|c|c|c|c|c|}
\hline Administrative district & Nuclear test number (date) & Location & Past image & Present image \\
\hline \multirow{6}{*}{$\begin{array}{l}\text { Punggye-ri, } \\
\text { Kilju county, } \\
\text { North Hamgyong } \\
\text { province }\end{array}$} & First (2006.10.9) & $\begin{array}{r}42.28^{\circ} \mathrm{N} \\
129.10^{\circ} \mathrm{E}\end{array}$ & & \\
\hline & Second (2009.5.25) & $\begin{array}{c}41.28^{\circ} \mathrm{N} \\
129.09^{\circ} \mathrm{E}\end{array}$ & $\frac{13}{32}$ & \\
\hline & Third (2013.12.2) & $\begin{array}{l}41.28^{\circ} \mathrm{N} \\
129.06^{\circ} \mathrm{E}\end{array}$ & & \\
\hline & Fourth (2016.1.6) & $\begin{array}{c}41.23^{\circ} \mathrm{N} \\
129.18^{\circ} \mathrm{E}\end{array}$ & & \\
\hline & Fifth (2016.9.9) & $\begin{array}{l}41.299^{\circ} \mathrm{N} \\
129.079^{\circ} \mathrm{E}\end{array}$ & & \\
\hline & Sixth (2017.9.3) & $\begin{array}{l}41.343^{\circ} \mathrm{N} \\
129.036^{\circ} \mathrm{E}\end{array}$ & & \\
\hline
\end{tabular}

Note. Circles inside images represent the testing site of each nuclear test. 
If there is any radiation leak and environmental destruction after nuclear tests in North Korea, it is necessary to analyze their actual level based on scientific and objective data. The satellite images of Google Earth used in this study provide $25 \mathrm{~m}$-resolution SPOT images as basic data, and $60 \mathrm{~cm}$-resolution QuickBird images are additionally available for major cities and military facilities. Most of the images were taken after 2005, and the date and year of the images were provided by Google Earth with images (Bae, 2010).

In particular, images provided by Google Earth can be conveniently compared with those taken in the past using a function of viewing historical imagery. Users can also add an icon to spot an exact location by entering latitude and longitude information, which allows users to see how the environment of the place has changed over time visually. However, recent images for some areas are not available, and thus it is difficult to compare differences between the past and present conditions of those areas.

This study aimed to examine environmental destruction caused by six rounds of nuclear tests in North Korea by comparing images before and after the nuclear tests. In particular, areas related to forest destruction were focused on in this study. In many cases, forest destruction is associated with changes in geological and geographical features, which in turn accelerates radiation leaks or spreading. To do so, this study compared images before and after the nuclear tests in order to identify the location of each nuclear test and changes in the color and shape of their surrounding areas and thus to examine their impact. Despite the limitations of comparison based on Google Earth images, this study aimed to identify whether forest destruction was directly caused by nuclear tests or indirectly caused by earthquakes or landslides after nuclear tests, and to compensate the limitations through literature review.

The location of six nuclear test sites conducted in Punggye-ri identified on Google Earth images is as shown in Fig. 3, and the conditions of surrounding areas before and after nuclear tests were as shown in Table 1. Fig. 3 shows the location and date of nuclear tests, and the magnitude of earthquakes caused by nuclear tests. Each nuclear test was carried out within very close proximity, and in particular those from the fourth to the sixth tests seemed to be conducted in almost the same place.

\section{Results and Discussion}

As North Korea has continued to conduct nuclear tests, it has been reported that their explosive power has also increased, and there is a growing concern about radioactive pollution and environmental destruction. Experts at home and abroad said that no radioactive substance was detected in the air after nuclear tests, but the possibility that North Korea might push ahead nuclear tests without proper safety measures in place cannot be excluded. There is still anxiety over the possibility that radioactive substances might flow through groundwater.

In addition, since experts express different opinions, it is necessary to provide more reliable, scientific and accurate information and knowledge for the public. In terms of environmental destruction, the magnitude of the earthquake observed after the sixth nuclear test was 6.3, and the seismic vibration was detected in some regions in China and Russia. Satellite images showed that rocks on Mt. Mantap composed of rock were broken and crumbled with soil, which changed geographical features and raised the possibility of the destruction of ecosystem (Kim, 2012).

Analyzing spatial images of Google Earth is an effective way to compare and analyze past and present images. In this study, the impact of nuclear tests on environment was analyzed using past and present Google Earth images, and environmental pollution around the nuclear test sites was also analyzed.

The impact of nuclear tests on natural environments is well shown in Table 1, and the following findings can be reached by analyzing the images. First, the six nuclear tests can be divided into two categories based on their size and location. In terms of their size, they can be grouped into the 1st-2nd tests, the 3rd-5th tests, and the 6th test. In terms of their impact on environments and forests based on their spatial location, they can be grouped into the 1st-3rd tests, and the 4th-6th tests, which shows higher explanation power (Figs. 3 and 4).

Second, after the first, second and third nuclear tests, the share of green spaces in their test sites was found to 
be significantly reduced. In particular, when images before and after the second nuclear test were compared, the slight subsidence of the ground was observed. This kind of subsidence can be caused by the shaft created in the mountainside, and lead to cracks in rocks around the mountain, radiation leaks and groundwater pollution. Since it is difficult to identify the level of leaks of radioactive substances with Google Earth spatial images, this study did not discuss radiation leaks. Still, it is needed to discuss radiation leaks caused by nuclear tests using engineering techniques in follow-up studies. The direct and indirect impact of the 1st-3rd nuclear tests on forest destruction is shown in Figs 5 and 6. Fig. 6 shows that the size of earlier nuclear tests compared to the fifth and sixth tests that were more recently conducted was smaller, and thus that they seemed to indirectly affect earthquakes through changes in geographical features, rather than affecting earthquakes directly (Hilpert and Meier, 2018). These results coincided with the conclusion of Zhang and Wen (2013) that analyzed the impact of the 1st-3rd nuclear tests on earthquakes. These results indicate that ultimately forest destruction that is indirectly caused by earthquakes or landslides due to changes in geographical features, or forest destruction that is directly caused by nuclear tests can result in the subsidence of rocks or bedrocks, and thus radiation leaks.

Third, after the 4th-6th nuclear tests, the subsidence of the ground and forest destruction were observed not in the nuclear test sites, but in their surrounding areas. In particular, it was observed that the geographical structure and forests of their surrounding areas were seriously destroyed after the fifth and sixth tests. The actual impact of nuclear tests on the geographical structure and features of the areas is expected to be much higher than the level that was exposed outside, and for this reason additional studies and measures need to be established. The impact can lead to large-scale disasters like earthquakes and landslides, which

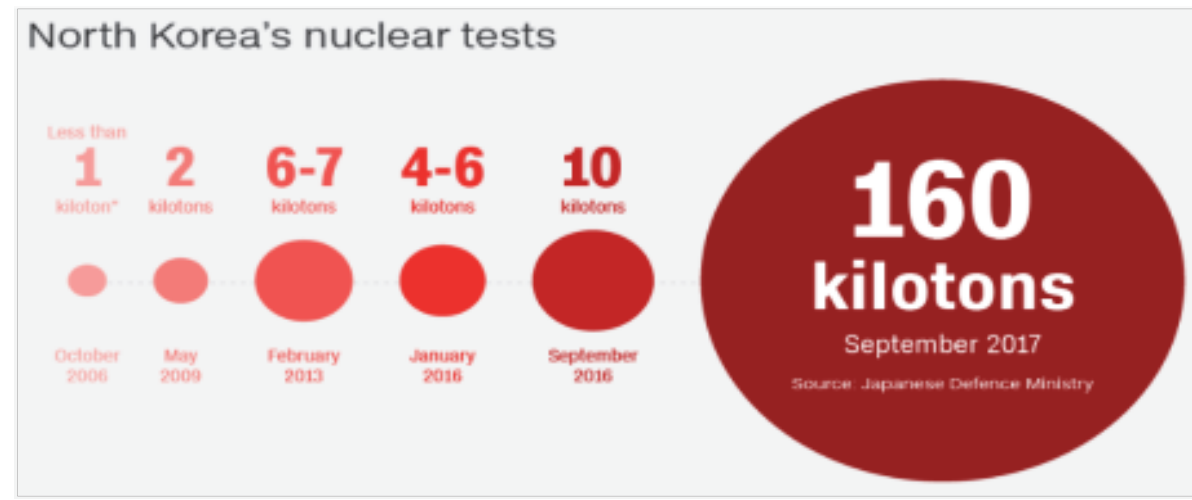

Fig. 4. North Korea's nuclear tests explosion impact ( 1 kiloton=1,000 tons of TNT). Reprinted from "North Korea's nuclear test caused collapse, study says," by J. Berlinger and S. Wang, 2018, April 26, CNN news.

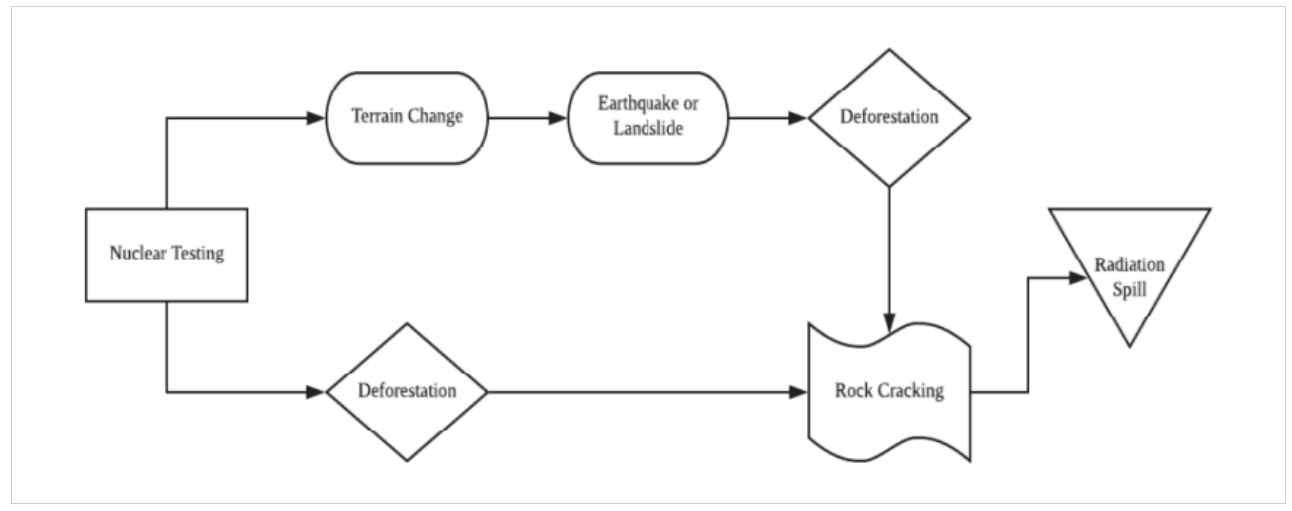

Fig. 5. Direct and indirect effects caused by the first, second, and third Punggye-ri nuclear tests. 


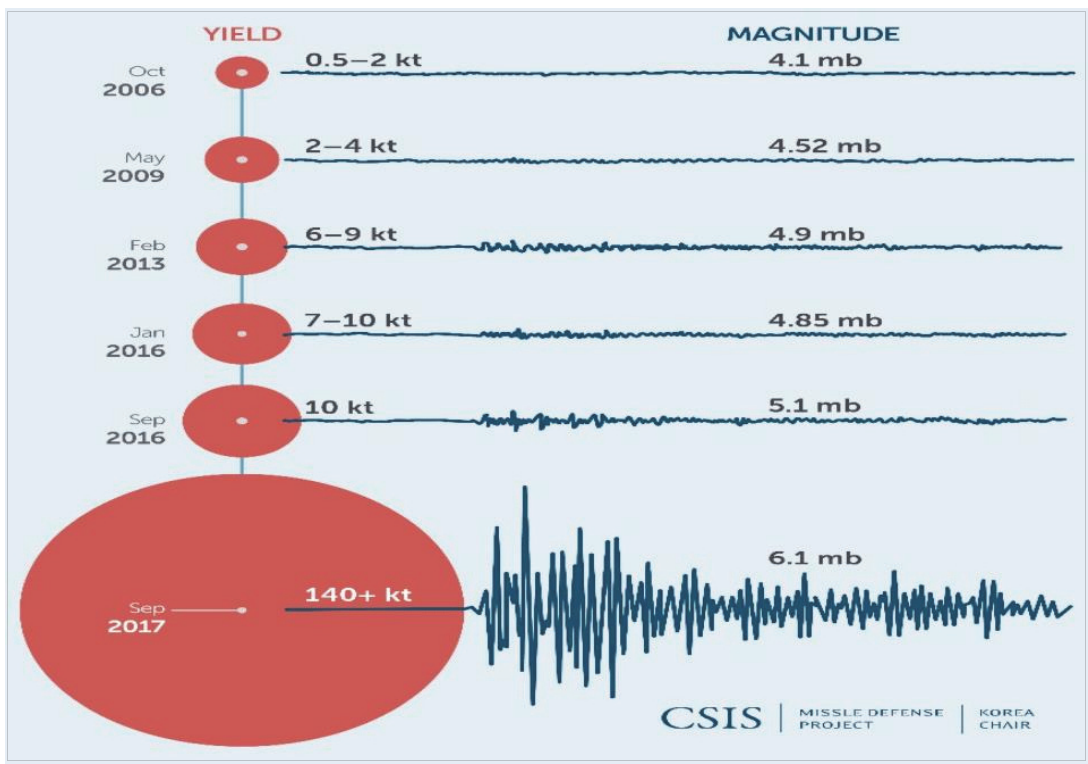

Fig. 6. North Korean nuclear tests and their seismic impact, October 2006 to September 2017. Yield in 1,000 tonnes $(\mathrm{kt})$ TNT equivalent. Magnitude $(\mathrm{mb})=$ Strength of the seismic waves triggered by the nuclear test. Reprinted from "Facets of the North Korea conflict: Actors, problems and Europe's interests,"by H.G. Hilpert and O. Meier (Eds.), 2018, SWP Research Paper, German Institute for International and Security Affairs.

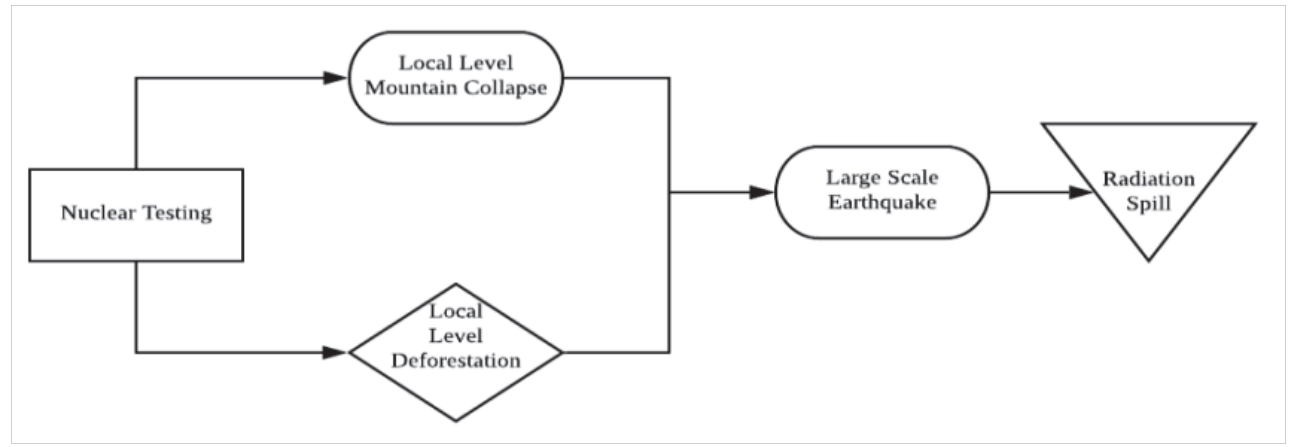

Fig. 7. Direct and indirect effects caused by the fourth, fifth, and sixth Punggye-ri nuclear tests.

can result in massive casualties. Compared to the 1st-3rd nuclear tests, the explosive power of the 4th-6th nuclear tests was much higher, and therefore the magnitude of earthquakes can increase. These earthquakes can result in radiation leaks both directly and indirectly. For this reason, it is essential to jointly respond to the risk of these large-scale disasters through international cooperation, and this especially can be done through political, economic and military pressure. The impact of the 4th-6th nuclear tests is as shown in Fig. 7. This shows that local landslides and forest destruction can cause large-scale earthquakes and radiation leaks, which is in line with the images of synthetic aperture radars (SARs) analyzed by Lewis (2017). Lewis
(2017) argued that since the scale of the sixth nuclear test, in particular, was very large, it resulted in not just changes in features, but also the collapse of the mountain, increasing the risk of secondary earthquakes based on significant changes in the elevation of the top of the mountain (Lewis, 2017). These changes in the elevation were not observed after the 1st-3rd nuclear tests, demonstrating the seriousness of the sixth nuclear test. As the results show, forest destruction was not just a natural phenomenon, but can be utilized as an indicator of the secondary and tertiary effects of nuclear tests.

Environmental destruction and pollution are not the problems of North Korea only, but the problems that neigh- 
boring countries should solve together. If spatial image analysis systems like Google Earth are established continuously, the efforts can lead to the smooth establishment of cooperative governance together with North Korea for environmental improvement and land development, and this kind of analysis systems can be directly utilized in restoring the land and environment of North Korea if the reunification of North and South Koreas (Ki et al., 2017).

\section{Conclusion}

The reason why environmental pollution and destruction of natural environments need to be urgently managed through scientific analysis and cooperation in the fields of science and technology is that the problems have seriously affected North Korean society. To overcome restrictions such as a limited access to and lack of information on the environment of North Korea, tools like Google Earth need to be utilized to continuously survey environmental conditions from a technical perspective, to establish cooperative governance from an administrative perspective, and thus to continue to cooperate with North Korea regardless of political conditions.

This study was conducted based on the geographic information of Google Earth established by earlier studies and the results of analysis of Google Earth images. In the process, literature review was simultaneously conducted to examine environmental pollution or destruction of natural environments caused by North Korea's nuclear tests, and the following conclusions were reached.

First, after the 1st-3rd nuclear tests were conducted in the early stage, the share of green spaces was significantly reduced. In particular, when images before and after the second nuclear test were compared, the slight subsidence of the ground was also observed. This kind of subsidence can be caused by the shaft created in the mountainside, and lead to cracks in rocks around the mountain, radiation leaks and groundwater pollution. Since it is still difficult to identify the level of leaks of radioactive substances with Google Earth spatial images, this study did not discuss radiation leaks. The images after the 1st 3 rd nuclear tests showed that indirect forest destruction that is indirectly caused by earthquakes or landslides due to changes in geographical features, or forest destruction that is directly caused by nuclear tests can result in the subsidence of rocks or bedrocks, and thus radiation leaks.

In addition, after the 4th-6th nuclear tests, the subsidence of the ground and forest destruction were observed not in the nuclear test sites, but in their surrounding areas. In particular, it was observed that the geographical structure and forests of their surrounding areas were seriously destroyed after the fifth and sixth tests. The images of the 4th-6th nuclear tests showed that local landslides and forest destruction can cause large-scale earthquakes and radiation leaks.

Regarding North Korea's nuclear tests and their impact on natural environments, various types of cooperative governance need to be established utilizing the South Korean government, the private sector, the academia, NGOs and international organizations in order to plan and prepare various policies that can reduce environmental pollution and environmental destruction in North Korea. To do so, the South Korean government need to urgently plan and prepare a mid- and long-term roadmap.

In particular, as an approach to forest destruction caused by North Korea's nuclear tests, it will be effective to establish and utilize cooperative governance for disasters, assuming that problems associated with nuclear weapons can be addressed by the denuclearization of North Korea (Ki, 2015). The conditions and situations of cooperative governance for disasters for North and South Koreas are as follows. First, it will give South Korea an opportunity of collecting information on North Korea, and North Korea benefits of prompt responses to different types of disasters. Second, North Korea needs to ask South Korea for cooperation for repairing damage from disasters, and South Korea, in turn, needs to accept the request, forming a cooperative relationship between the two. Third, it is also necessary to ensure organizations and companies that can participate in restoration activities for North Korea are ready when disasters occur in North Korea. Lastly, North Korea needs to express a will to improve inter-Korean relations through disaster restoration activities and joint research. Unless these conditions are met or these situations are set, it will be difficult to restore forest destruction through cooperation 
governance for disasters.

In order to apply cooperative governance for disasters between the two Koreas in reality, either the government or government-sponsored organizations need to play a role as a control tower, and strategies for restoring destroyed forests into their original state through various cooperative channels need to be established (Ki, 2015). Assuming that cooperative relations can be created between North and South Koreas through efforts such as denuclearization of North Korea, international cooperation and academic approaches can be important channels for this kind of cooperative governance. In addition, it will be also meaningful to develop methods and policies to advance them into universal analysis technologies that can be utilized not only in special situations like nuclear tests, but also disasters such as floods and forest fires through this study.

\section{References}

Bae, S.H. 2010. Landscape resource assessment using Web 2.0-based geographic information. J. Assoc. Korean Photo Geogr. 20(3):1-12. https://doi.org/10.35149/jakpg.2010. 20.3.001

Berlinger, J. and Wang, S. 2018, April 26. North Korea's nuclear test caused collapse, study says. CNN news. Retrieved from https://edition.cnn.com

Cho, M.H. 2015. Management of forest fire information using spatial image GIS technology. Mag. Korean Soc. Hazard Mitig. 15(5):28-34.

Ham, J.H. 2017, September 7. Concerns about radiation and fallout from North Korea's nuclear test..The numbers near the border with China are rising. VOA. Retrieved from https://www.voakorea.com/a/4017916.html

Hilpert, H.G. and Meier, O. (Eds.). 2018. Facets of the North Korea conflict: Actors, problems and Europe's interests [SWP Research Paper]. Berlin, Germany: German Institute for International and Security Affairs.

Hong, K.H. 1993. Radiative contamination of the marine environment due to the development of nuclear industry. Ocean Policy Res. 8(2):439-472.

Jang, E.C. 2017. Research into modeling of North Korea's nuclear experiments according to the radiative virtual leak scenario. Proceedings of annual fall conference of Korean Meteorological Society (pp. 138-139). Pusan, Korea.

Je, I.Y. and J.S. Jeon. 2008. Discrimination study for natural earthquake and artificial explosion in the Korean Peninsula (Report No. CATER 2006-5103). Seoul, Korea: Korea Meteorological Administration.

Jeon, K.W. 2017, September 6. 38 North "Northern Punggye-ri mountain range, landslide occurred due to nuclear test"North Korea's sixth nuclear test has caused extensive regional damage...There's no sign of a breach-. NewDaily. Retrieved from http://www.newdaily.co.kr

Jung, H.S. and B.S. Byun. 2011. Environmental policy. Seoul, Korea: Park Young Sa.

$\mathrm{Ki}$, J.H. 2015. Building a collaborative governance for South and North Korea's cooperation in science and technology. GRI Rev. [Gyeonggi Research Institute] 17(1):25-46.

Ki, J.H. 2016. Spatial photo analysis using Google Earth images to measure urban environmental pollution and deforestation in North Korea. J. Environ. Policy Adm. 24(1):133-146. https://doi.org/10.15301/jepa.2016.24.1.133

Ki, J.H., K.S. Hur, and S.W. Nam. 2017. A study of collaborative governance for environmental cooperation between South and North Korea using Google Earth-based spatial image. J. People Plants Environ. 20(1):65-72. https://doi.org/10.11628/ksppe.2017.20.1.065

Kim, C.H., E.H. Lee, S.J. Kim, and S.H. Bae. 2012. The analysis of the lake in North Korea using Google Earth. J. Assoc. Korean Photo Geogr. 22(2):29-38. https://doi.org/10.35149/jakpg.2012.22.2.003

Kim, J.M. 2012. North Korea's third nuclear test and a volcanic eruption at Mount Baekdu. Northeast Asia Strategic Analysis. Seoul, Korea: Korea Institute for Defense Analyses.

Kim, T.I. 2017, September 5. China research team "Pyonggye-ri nuclear test site, North Korea in danger of collapse". Yonhap News. Retrieved from https://www.yna.co.kr

Lewis, J. 2017, September 13. SAR image of Punggye-Ri [Blog]. Arms Control Wonk. Retrieved from https://ww w.armscontrolwonk.com/archive/1203852/sar-image-ofpunggye-ri/

Pabian, F.V. 2018, May 23. The Punggye-ri nuclear test 
site: A test tunnel tutorial. 38 North. Retrieved from https://www.38north.org/2018/05/punggyetunnel052318

Prăvălie, R. 2014. Nuclear weapons tests and environmental consequences: A global perspective. Ambio 43(6):729-744. https://doi.org/10.1007/s13280-014-0491-1

Song, Y.D. 2012, May 30. North Korea's drought and food increase cataclysmic warfare [Song Young-dae column]. RFA. Retrieved from https://www.rfa.org

Zhang, M. and L. Wen. 2013. High-precision location and yield of North Korea's 2013 nuclear test. Geophys. Res. Lett. 40(12):2941-2946. https://doi.org/10.1002/grl.50607 